\title{
A EFETIVAÇÃO DOS DIREITOS HUMANOS: UMA OBRIGAÇÃO DO ESTADO BRASILEIRO, NUMA PERSPECTIVA GRAMSCIANA
}

\author{
Roberto Galvão Faleiros Júnior \\ 5 Ano do Curso de Direito na Universidade "Júlio de Mesquita Filho" UNESP-Franca/SP \\ e-mail: robfaleiros@yahoo.com.br
}

RESUMO: Os Direitos Humanos são utilizados para fundamentar uma visão jusnaturalista do Direito, afastada do componente histórico-material de composição e dialeticidade da sociedade. Essa apropriação permite que princípio, valores, idéias sejam direcionados para a continuidade da exploração das camadas subalternas da sociedade - da classe excluída econômica, política e socialmente - perpetuando um ciclo de dominação que tem sua origem na estruturação do próprio capitalismo. Baseado nas categorias gramscianas e com fundamento no Direito Alternativo, podemos utilizar os Direitos Humanos como uma conquista histórica da humanidade, o que permite situarmos a sua teorização e aplicação numa clara perspectiva histórico-material, sendo parte de uma ampla e característica guerra de posições. Essa utilização dos Direitos Humanos nos permite vislumbrar uma sociedade amplamente democrática e igualitária, com referenciais axiológicos diferenciados dos quais partilhamos atualmente; com estruturas políticas e sociais participativas. Com um direcionamento prático-teórico e utilização dos basilares desses direitos, conhecidos também como fundamentais, conseguiremos mudar o foco dos anseios da humanidade da busca pela acumulação material para a busca da sobrevivência do homem - resgatando sua dignidade -; da supervalorização do indivíduo ante o coletivo para um equilíbrio entre o indivíduo e sua comunidade; da dominação de uma classe pela participação política-social de todas as classes. No entanto, para a sobrevivência do próprio homem, só conseguiremos atingir essa almejada mudança de objetivos da humanidade com uma irrestrita, ampla e profunda revolução cultural, uma verdadeira alteração de paradigmas e princípios, substituindo valores individuais por valores coletivos, aplicando os Direitos Humanos como princípio de vida coletiva.

PALAVRAS-CHAVE: Direitos Humanos. Gramsci. Estado. Materialismo Histórico. 
A constituição do sentido de Direitos Humanos, e sua conseqüente evolução acompanham a formação do Estado liberal-burguês e consolidam-se nos fundamentos do próprio sistema capitalista. A estruturação social e econômica burguesa é requisito garantidor e basilar para a formação desses direitos fundamentais. Dessa forma, são utilizados por uma visão jus-naturalista do Direito, fundamentando seu nascimento na metafísica, na natureza humana, em algo superior à realidade material, palpável, objetiva, concreta. Essa fundamentação é reconhecidamente afastada do componente histórico-material de composição e dialeticidade da sociedade. Essa apropriação jus-naturalista possibilita que princípios, valores, idéias e práticas sejam direcionados para a continua exploração das camadas subalternas da sociedade - da classe excluída econômica, política e socialmente - perpetuando um ciclo de dominação que tem sua origem na estruturação e fundamentação do próprio capitalismo. Uma sustentação cínica, que trata as desigualdades sócio-econômicas como naturais, próprias da natureza humana, e inerentes à composição social. No entanto, o progressivo reconhecimento e normatização (pelo menos) desses direitos são uma óbvia conquista histórica da humanidade, fruto da dinâmica social, suas constantes transformações, dos embates sociais e da organização e luta popular.

Baseado nessa visão histórico-material da sociedade, e buscando fundamentos na práxis Alternativa, ou seja, com elementos prático-teóricos do denominado Movimento do Direito Alternativo, podemos e devemos utilizar os Direitos Humanos como parte dessa conquista histórica da humanidade, como fruto de uma progressiva, porém revolucionária, evolução/superação dos conflitos de classe, possibilitando situar a sua teorização e aplicação através do materialismo histórico-dialético, sendo elemento crucial para nortear uma ampla e característica guerra de posições. Com esses fundamentos, os Direitos Humanos, são instrumentalizados para a superação desse bloco histórico, para a transformação e modificação da organização social.

Com esses direcionamentos iniciais, pretende-se retratar as formas de efetivação e aplicação desses direitos fundamentais no caso específico da sociedade brasileira; para isso, mapearemos como ocorrem as relações sociais e analisaremos as condições sócio-econômicas da população brasileira para 
identificarmos os meios, os mecanismos mais eficazes para efetivação concreta das diversas dimensões dos Direitos Humanos.

Após esse apanhado da organicidade social brasileira, analisaremos partindo da identificação dos mecanismos para a efetivação desses direitos - qual a real obrigação do Estado Brasileiro nesse panorama de descaso histórico com as classes subalternas. Entenderemos e conceituaremos mais amplamente este Estado, a partir da categoria grasmciana de "Estado Ampliado", ou seja, a obrigação da efetivação e aplicação dos Direitos Humanos não é apenas do Estado (estritu sensu), da sociedade política, entendida também como os aparelhos coercitivos de estado; mas essa obrigação e responsabilidade recaem também sobre a sociedade civil; dos aparelhos privados de hegemonia, ou seja, dos partidos políticos, das igrejas, das organizações civis, dos sindicatos, etc. Com o reconhecimento dessa responsabilidade a sociedade civil brasileira, será parte atuante na edificação de outros paradigmas sociais, alicerçada na analise material-histórica de construção dos Direitos Humanos, será peça fundamental para a superação das desigualdades sociais e para a transformação do modelo econômico.

Utilizando a concreta efetivação dos Direitos Humanos para direcionar e alicerçar uma sociedade amplamente democrática e igualitária, com referenciais axiológicos diferenciados dos quais partilhamos atualmente; com estruturas políticas e sociais participativas, norteados pelo princípio da dignidade da pessoa humana e do respeito e reconhecimento das coletividades, num direcionamento prático-teórico e numa perspectiva histórico-material, com atitudes revolucionárias. Essa efetivação possibilitará a mudança de foco dos anseios da humanidade, da busca pela acumulação material para a busca da vivência do homem (no, para e com ele) resgatando sua dignidade -; da supervalorização do indivíduo ante o coletivo para um equilíbrio entre o indivíduo e sua comunidade; da dominação de uma classe pela participação política-social de todas as classes; da supervalorização do cientificismo para um reconhecimento da cultura popular; da educação tradicional, direcionada para o mercado, para uma educação emancipatória.

No entanto, para o próprio progresso e sobrevivência dos recursos naturais e pela sobrevivência do próprio homem, só conseguiremos atingir essa almejada mudança de objetivos da humanidade com uma irrestrita, ampla e profunda revolução cultural, uma verdadeira alteração de paradigmas e princípios, 
substituindo valores individuais por valores coletivos, aplicando os Direitos Humanos como princípio de vida coletiva. Devemos buscar incessantemente as formas para efetivar esses direitos, alicerçando a construção concreta de uma sociedade socialista.

Almejando encontrar fundamentos para a realização deste objetivo, enumeramos a clara necessidade de utilizarmos e entendermos os Direitos Humanos como conquista histórico-social da humanidade é evidente. Devemos, portanto, desconsiderar, fundamentações jus-naturais, que permitiram ao longo da história humana, o alheamento do indivíduo e da própria sociedade em relação às construções e manutenções das desigualdades materiais e sociais. Assim, utilizando abertamente categorias do pensamento gramsciano, buscaremos fundamentos teóricos e também estratégias práticas, para situarmos a efetivação dos Direitos Humanos como uma obrigação tanto da sociedade política quanto da sociedade civil brasileira. Assim, devemos pontuar as respectivas parcelas de responsabilidade de cada amplitude social para entendermos o processo de reformismo do sistema capitalista, que historicamente utiliza o reconhecimento de alguns direitos apenas como forma de controle social, tentando apaziguar qualquer insurgência social.

O estudo dos Direitos Humanos nos permite entre outras constatações, de nos reconhecermos e de nos visualizarmos no outro ser humano. Somos parte da mesma composição social, vivemos no mesmo mundo, e mesmo assim o ser humano, não reconhece a dignidade do ser alheio.

Com a inquietação de conviver e presenciar as desigualdades e os descasos com camadas da sociedade brasileira historicamente excluída, objetiva-se a constatação de condicionantes do sistema capitalista que permitiram a uma pequena elite burguesa, protagonizar uma "revolução passiva" ao longo da estruturação do Brasil República. A manutenção no poder alicerçada, entre outros fatores, na normatização de alguns direitos, de algumas dimensões dos chamados Direitos Humanos, desconectando assim, a base material da sociedade do que é positivado neste país e o que é realmente aplicado e efetivado.

Outro aspecto que certamente dificulta a apreciação desses direitos é o próprio caráter patrimonialista e a visão individualista - herança da proclamada revolução burguesa - dos códigos e dos operadores jurídicos, já que com uma visão obtusa do fenômeno jurídico e de sua real função perante a sociedade 
impossibilitam a identificação das contradições inerentes ao embate social e a correlação de forças dos diversos movimentos sociais.

Uma outro aspecto muito defendido para o não reconhecimento dos Direitos Humanos é a proclamada segurança jurídica, que defendida em grande parte para a manutenção do status quo, para a defesa e para a manutenção de estruturas antigas e ultrapassadas, impossibilita que a sociedade contemporânea desenvolva a sua concepção de Direito e de Justiça, em busca de uma transformação social.

Com essas constatações fica mais fácil a análise das obrigações e responsabilidades da sociedade política e da sociedade civil brasileira, no reconhecimento e na efetivação de todas as dimensões dos Direitos Humanos em benefício das camadas subalternas da sociedade.

Para essa análise histórica da normatização e pouco efetiva aplicação dos Direitos Humanos utilizaremos o método do materialismo histórico-dialético como forma de compreender as determinantes do modo de produção capitalista (já que vimos sob ele), com suas condições materiais de produção e da sua forma de divisão social do trabalho, que influenciam todo o modo e organização da vida humana, condicionando o reconhecimento, normatização e efetivação dos Direitos correspondentes aos interesses da classe dominante.

Mesmo sendo parte imprescindível do método descrito acima, vale ressaltar, devido à sua indubitável importância nas análises críticas, a Dialética, entendida e utilizada nesta perspectiva também como método para sua conclusão. Primeiramente indagamos se há possibilidade de separação entre o método cientifico e o método filosófico, para podermos posteriormente determinar a caracterização do método dialético.

O método cientifico encontra respaldo dentro da realidade na qual estamos inseridos, buscando de todas as formas uma verdade empírica, um rigor de resultados, por isso é um método que almeja confirmar experimentalmente a realidade, analisando fenômenos do mesmo tipo, dentro de limites específicos; sendo assim ele não se universaliza, sendo, portanto limitado, podendo ser aplicado somente entre fenômenos ligados entre si. Esse método poder ser considerado como o único caminho para conhecer a realidade, dessa forma é o modelo de ciência da modernidade. A ciência não pode se separar do método experimental, se é ciência verificável experimentalmente, não pode ser universalizado. Já o método 
filosófico encontra-se fora do campo dos fenômenos, ele é baseado na especulação, na escolha, é um método valorativo que se deparara no ambiente metafísico, sendo produzido através de elucubrações. O método filosófico provoca o avanço do campo do conhecimento puxando o método cientifico.

Agora, se entendermos o método dialético como uma forma de pensar, de organizar as idéias e considerando os dois métodos acima, trataremos a dialética como um método de exposição para o que já foi investigado e para reconstrução do saber autentico, sendo assim não é enclausurado, é um método de ciência. Temos então, no método dialético, uma forma de superação do conhecimento, evolução, uma foram de produção.

Ainda, quando falamos em "processo de conhecimento" nem sempre queremos nos referir a um conhecimento cientifico. Desse modo, para obtermos qualquer tipo de conhecimento, devemos levar em consideração inúmeros fatores; quais sejam, a imaginação, o inconsciente, a observação, assim como qualquer outro fator que nos permita especular. Contudo, a fim de transformarmos tal conhecimento em algo científico, ocorre a necessidade de buscarmos uma prova experimental. É dentro desse contexto que podemos falar em método filosófico, científico e também em dialética. O primeiro, como uma especulação metafísica, procura trabalhar dentro da universalização dos fenômenos. Já o segundo, tido como uma forma experimental, de conhecer a realidade, estudada na medida em que só pode ser considerado dentro de contextos interligados, não se universalizando. É importante, no entanto, destacar a necessidade de um em relação ao outro: o método filosófico ao especular sobre os fenômenos e questionar sobre eles acaba por impulsionar o cientifico, que por sua vez, nos permite conhecer a realidade.

A partir desse ponto, a dialética apresenta-se como um verdadeiro método de produção de conhecimento, através da superação e ao levar em consideração não apenas o método cientifico e o filosófico, mas também - e sem estabelecer uma ordem - o de investigação e de exposição, também muito discutidos. No nosso entender o método de investigação levaria em consideração aspectos sensoriais e experimentais ao passo que o de exposição buscaria uma ordenação e reconstrução do pensamento. 
Assim, a dialética acaba por abranger uma pluralidade de métodos, estando dentro de um contexto histórico multifacetário, condizente com nossa realidade.

Dentro de todas essas perspectivas, o direito moderno, e conseqüentemente os Direitos Humanos, passam por essas mudanças, em sua grande parte para atender aos valores e princípios mercadológicos. Mas nesse vácuo de conceitos e valores humanos, surge um pensamento contra-hegêmonico do fenômeno jurídico. Um pensamento que se origina e desenvolve-se à margem do sistema jurídico atual. Assim, o homem é entendido como ser e não como objeto, busca estar nos fundamentos dessa nova constituição de valores, dessa nova cultura jurídica. $O$ chamado Direito Alternativo rompe com formulações valorativas, regras e conceitos tradicionais e/ou moderno-formalistas para fundar as bases de uma nova concepção de um (e também desse) Direito. Essa nova forma de visualizar o Direito e as relações sociais - inseridas neste desgaste constante dos modelos arcaico de organização jurídico-social - almeja resgatar a dignidade perdida do ser humano.

Vivemos em um sistema neoliberal que busca ampliar o seu desenvolvimento de forma avassaladora, suplantando o desenvolvimento do ser humano, transformando-nos em uma sociedade doente, uma sociedade que tem uma necessidade de consumo e não uma sociedade de consumo de necessidades básicas e fundamentais para a sobrevivência de todos seus indivíduos, dessa forma os conflitos gerados e levados a Justiça são em grande parte, em torno de questões econômicas, já que estando em uma organização social excludente o conflito distributivo acaba ficando por traz dos conflitos inter-subjetivos.

Devemos construir uma visão antropocêntrica, ou indo mais longe, uma visão "altericêntrica" e não "marcadocêntrica" ou "capitalcêntrica" da humanidade. Façamos assim nossas análises concretamente para que não sejamos direcionados à busca infinita de "riqueza abstrata" (Marx), busquemos a riqueza humana, efetivemos os Direitos Humanos.

\section{REFERÊNCIAS BIBLIOGRAFICAS}

RÚBIO, David S.(Org), FLORES, Joaquín Herrera (Org) e CARVALHO, Salo de (Orgs.). Direitos Humanos e Globalização Fundamentos e Possibilidades desde a Teoria Crítica. Rio de Janeiro, Lúmen Júris, 2004. 
SARLET, Ingo Wolfgang. A Constituição Concretizada: construindo pontes com o público e o privado. Porto Alegre: Livraria do Advogado, 2000.

SARLET, Ingo Wolfgang. A Eficácia dos Direitos Fundamentais. 2.ed. ver. atual. Porto Alegre: Livraria do Advogado, 2001.

BONAVIDES, Paulo. Teoria Constitucional da Democracia Participativa. Por um Direito Constitucional de luta e resistência Por uma hermenêutica Por uma repolitização da legitimidade. São Paulos: Malheiros Editores LDTA, 2001.

PORTELLI, Hugues. Gramsci e o Bloco Historio; tradução de Angelina Peralva, Rio de Janeiro, Paz e Terra, 1977.

COUTINHO, Carlos Nelson (Org). TEIXEIRA Andréa de Paula (Org). Ler Gramsci, Entender a Realidade. Rio de Janeiro: Civilização Brasileira, 2003

CHAUÍ, Marilena. Convite à Filosofia. São Paulo: Ática, 1995

MINAYO, Maria Cecília de Souza (Org). Pesquisa Social. Teoria, Método e Criatividade. Petrópolis, RJ: Vozes, 1994.

HARNECKER, Marta. Os conceitos elementares do Materialismo Histórico. São Paulo: Global, 1983. 